Vol. 17 (2008): 325-337.

\title{
Are larger farms more efficient? A farm level study of the relationships between efficiency and size on specialized dairy farms in Sweden
}

\author{
Helena Hansson \\ Swedish University of Agricultural Sciences, Department of Economics, PO Box 7013, \\ SE-75007 Uppsala, Sweden,email: helena.hansson@ekon.slu.se
}

\begin{abstract}
The study explored how economic, technical and allocative input efficiencies in specialized Swedish dairy farms are affected by differences in farm size. The efficiency analysis showed that costs could decrease by $30 \%$ if all farms were as efficient as the best farms in the sample. The effect of farm size was analysed in second-stage regressions. Two measures of farm size were considered: income from dairy and the number of hectares, together with squared measures of both size measures and variables to control for geographic location. The results showed that the relationships between farm size and efficiency can be described as non-linear, where efficiency first tends to decrease with size and then increase. The average scale efficiency was $94.7 \%$, suggesting that, on average, the farms are close to their optimal scale. The paper concludes by suggesting that farm efficiency can be increased both by focusing on increasing the knowledge about how inputs can be more optimally combined and by growth of the farms. However, the latter suggestion requires farm growth aiming at the larger farm segments.
\end{abstract}

Key-words: Dairy farms, data envelopment analysis, efficiency, farm size, Sweden, tobit regression

\section{Introduction}

During the last decades, Swedish dairy production has undergone extensive structural changes at the farm level. From 1990 to 2006, the number of dairy farms decreased by about $69 \%$, meanwhile the amount of milk produced only decreased by $9 \%$ (Statistics Sweden 2007). During the same time period, the mean herd size more than doubled, from 22 to 48 cows (Statistics Sweden 2007). This implies that small farms change to other production lines, go out of business or merge with other farms. The trend is not unique for Sweden; decreases in the 


\section{AGRICULTURAL AND FOOD SCIENCE}

Hansson, H. Are larger farms more efficient?

number of dairy farms are also reported in other North European countries, meanwhile the size of the dairy herds grows at a rapid speed (Statistics Sweden 2002, 2006). For example, from 1997 to 2003, the number of Finnish dairy farms decreased by $35.5 \%$ (Statistics Sweden 2002, 2006). At the same time the average Finnish dairy herd grew 35\% to 17.5 cows (Statistics Sweden 2002, 2006). In Denmark, the number of dairy farms decreased by $39 \%$ from 1997 to 2003, while their average herd size grew by $44 \%$ to 75 cows (Statistics Sweden 2002, 2006). Similar trends, i.e. fewer and larger dairy farms, are also reported for the U.S (Tauer and Mishra 2006, MacDonald et al. 2007).

A clear reason underlying the described structural changes is the desire either to increase productivity and farm return by realizing returns to scale or to increase farm return by larger production volumes. Farm growth was stressed as crucial by Newman and Mattews (2006) who found a productivity growth rate of Irish dairy farms of $2 \%$ annually. They suggested that larger scale of dairy farms is necessary because the $2 \%$ are not sufficient to cover both inflation and possible declines in nominal milk prices.

A review of the literature on farm level efficiency in dairy and related farms shows that these farms have a large potential for increased returns if all farms were as efficient as the best farms. For example Oude Lansink et al. (2002) studied technical efficiency of Finnish farms, using the data envelopment analysis (DEA), and they found that the conventional livestock farms had technical efficiency scores of $69 \%$. Consequently, these farms should be able to reduce their costs by $31 \%$ if the average farms were as technically efficient as the best farms in the sample. Reinhard et al. (2000) studied a sample of Dutch dairy farms, using both the stochastic frontier approach (SFA) and DEA. They found an average technical efficiency score of $89 \%$ in the SFA case and $78 \%$ in the DEA case. The difference between the SFA and the DEA results is likely to depend on the deterministic nature of DEA, where all deviations from the efficient frontier are considered as inefficiency. Heshmati and Kumbhakar (1994) examined the technical efficiency in four panels of Swedish dairy farms, dur- ing 1976 to 1988, excluding 1985, using the SFA. They found that the average technical efficiency scores were located between $81 \%$ and $83 \%$ for all four panels.

Given the results in the reviewed literature, one urgent question is how the dairy farms can become more efficient. An approach observed empirically, in the structural changes in progress, is to enlarge farm size to realize cost advantages of larger scales, so-called economies of scale. In Sweden, this approach is also driven by policy makers such as dairy farm advisors, who encourage dairy farms to become larger. Furthermore, the observed approach is driven by technology developments which build on large loose housing systems. Nevertheless, the effect of farm size on dairy farm efficiency is not clear, and consequently it is unsure whether the outcome of a farm enlargement will be a more efficient farm. Penrose (1959) argues that firm inputs are indivisible, and that the desire to fully use all inputs triggers firm growth. However, growth then implies that some other input is not fully used, which arguably leads to inefficiency and inefficiency in production is consequently likely to remain.

Some authors have studied how dairy farm production is affected by farm size and suggest that technical efficiency is positively affected by farm size (Bravo-Ureta and Rieger 1991, Alvarez and Arias 2004, Barnes 2006, Hadley 2006) but that economic and allocative efficiencies are negatively affected by farm level size (Bravo-Ureta and Rieger 1991). These findings thus suggest that larger farms are better at using their inputs in a technically efficient way, but worse at combining their inputs in a optimal way taking prices into consideration. The applications in these three studies were made to New England (Bravo-Ureta and Rieger 1991), Spain (Alvares and Arias 2004), Ireland (Barnes 2006) and England and Wales (Hadley 2006). Karagiannis et al. (2002) found evidence of decreasing returns to scale in UK dairy farms, which suggests that in these farms, unit production cost will increase when the farms become larger. On the other hand MacDonald et al. (2007) found increasing returns to scale in U.S. dairy farms, suggesting cost advantages at larger farms. Outside the dairy sector, Helfand and Levine (2004) found a non-lin- 
ear relationship between the size of farms in Brazil and technical efficiency, where technical efficiency first decreased and then increased with size. Iráizoz et al. (2003) found no conclusive results on the relationship between technical efficiency and size, measured in terms of the total production, in horticultural production in Spain. Sharma et al. (1999) found a positive relationship between economic, technical and allocative efficiency and size, defined as the number of sows, in swine farms in Hawaii.

If we are to understand if and how the observed structural changes with fewer and larger dairy farms in the North European countries, are to lead to more efficient farms, further studies that analyse how farm size affects farm efficiency are needed. Unless increasing returns to scale, i.e. cost advantages of larger farms, are present, returns increase because production is scaled up. In this situation the inefficient production remains. Not only does the fact that previous literature show no clear, unambiguous relation between farm size and efficiency justify further studies, but more importantly: previous literature is not possible to generalize easily to e.g. north European countries because of differences in farming systems, climate and culture.

This study aimed to investigate how economic, technical and allocative input-oriented efficiencies were affected by differences in farm size in dairy farms in Sweden. Moreover, the study aimed to investigate the farm scale efficiencies and effects ${ }^{1}$ to further study the potential improvements in efficiency due to larger farms. The results showed that there is room for improvements in farm efficiency if all farms were as efficient as the best ones. Further, the results showed that the relationship between farm efficiency and size can be described as non-linear, where efficiency is first decreasing with farm size and then increasing.

1 Note that scale efficiencies and effects are not the same thing. See below.

\section{Method}

The study was conducted in three steps. First, farm economic, technical and allocative input-oriented efficiencies were estimated. The efficiency scores were based on the framework developed by Farrell (1957). Second, the influence of farm size on efficiency was determined. Third, farm level scale efficiencies and effects were assessed. The analysis builds on comparisons between farms with different levels of efficiency and size at a given point in time. This means that the dynamic aspect of farm growth is not incorporated in this study.

\section{A description of efficiency}

In efficiency studies, the input-oriented efficiency scores consider the cost side of a firm, by answering the question of how much costs can decrease through more efficient use and more optimal combination of inputs, while a given level of outputs is produced. Technical efficiency measures the extent to which the firm uses its inputs as intensely as possible. Allocative efficiency measures the extent to which the firm combines its inputs in the optimal combination, taking input prices into consideration. Economic efficiency is a combined measure of both technical and allocative efficiencies and thus measures the overall efficiency. If single output and two inputs are assumed, the three input-oriented efficiency scores can be shown graphically as in Figure 1.

The isoquant represented by YY' shows the technically efficient way of producing the given output Y. A farm situated somewhere along this isoquant is therefore technically efficient. The economically efficient point is at the tangency point between the isoquant and the isocost line PP'. At this point, the technical rate of substitution equals the economic rate of substitution. Assume a firm, which produces $\mathrm{Y}$ with the inputs $\mathrm{x} 1$ and $\mathrm{x} 2$, situated at the point $\mathrm{R}$. Its economic input-oriented efficiency is measured as the distance $0 \mathrm{R}$ ' divided by the distance $0 \mathrm{R}$. The technical efficiency of this firm is measured as the distance $0 \mathrm{Q}$ divided by the 
Hansson, H. Are larger farms more efficient?

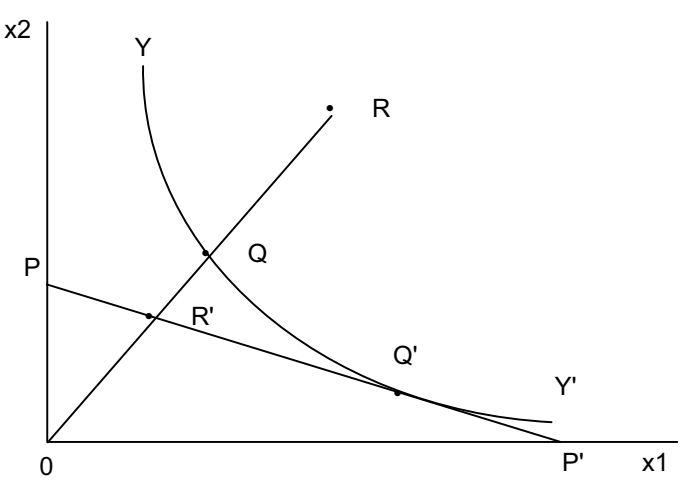

Fig. 1. Economic, technical and allocative input-oriented efficiency. Economic efficiency is measured as $0 \mathrm{R}^{\prime} / 0 \mathrm{R}$. Technical efficiency is measured as $0 \mathrm{Q} / 0 \mathrm{R}$. Allocative efficiency is measured as $0 \mathrm{R}^{\prime} / 0 \mathrm{Q}$.

distance 0R. Allocative efficiency, finally, is measured as the distance $0 \mathrm{R}$ ' divided by the distance $0 \mathrm{Q}$. Economic efficiency can then be recognized as the product of technical and allocative efficiencies. All efficiencies are measured in the interval $0-1$, where 1 indicates full efficiency. For a review of efficiency measures see e.g. Coelli et al. (2005)

\section{Step I: estimation of farm efficiency}

Data envelopment analysis, DEA (Charnes et al. 1978) was used to estimate the farm efficiency. DEA is a deterministic approach that uses linear programming to calculate the farm efficiency score. An alternative way of estimating efficiency scores is the stochastic frontier approach, SFA (Aigner et al. 1977, Meeusen and van den Broeck 1977) which makes use of econometric methods. DEA and SFA have been compared in several empirical settings, with the common result that they assess relative efficiency to the same firms and that the average efficiency scores are either equal or lower in DEA (Balcombe et al. 2006, Cullinane et al. 2006, Iráizoz et al. 2003, Coelli and Perelman 1999, Sharma et al. 1999, Resti 1997). Lower average efficiency scores in DEA are expected because DEA reports all deviations from the efficient frontier as inefficiency, whereas SFA reports some as stochastic variation. Both DEA and SFA are empirical methods, which implies that they construct efficient frontiers based on the most efficient firms in the sample at hand. The remaining firms get efficiency scores in relation to the efficient frontier. This means that the efficiency of one firm is measured in relation to the other firms in the sample. DEA was applied in this paper because we experienced advantages of it such as it does not require specification of functional form and that it allows easily for the decomposition of the economic efficiency score into its technical and allocative parts.

Before estimating the farm level efficiencies, an assumption about the scale at which the farm is operated is needed. Various constraints at the farm, such as financing and goals of the farmer can cause the farm to operate at a scale that is not long-run optimal from an economic point of view. Previous literature has found that at farms, other goals than profit maximizations influence the actions (e.g. Gasson et al. 1973, Lunneryd 2003). To account for this, variable returns to scale (VRS), which allows operation at all scales, was assumed when assessing the economic, technical and allocative input efficiencies.

\section{DEA equations to calculate economic, allocative and technical efficiency}

Assume $n$ farms, which use the input matrix $X$, to produce the output matrix $Y$. The input and output matrices of each individual farm, $i$, are $x_{i}$ and $y_{i}$ respectively. Further, assume that each farm faces a cost-minimizing input bundle, $x_{i}$ and an input price vector $w_{i}$. In this setting, the DEA economic input efficiency scores were obtained by first solving the following linear programme:

$\begin{array}{ll}\text { Subject to } & -y_{i}+Y \lambda \geq 0, \\ & x_{i}^{*}-X \lambda \geq 0 \\ & N 1^{\prime} \lambda=1 \\ & \lambda \geq 0\end{array}$


Vol. 17 (2008): 325-337.

where $w_{i}^{\prime} x_{i}^{*}$, would be the minimum cost of farm $i$ if it was as efficient as the most efficient farm in the sample. The economic efficiency score of each farm was obtained by comparing the minimum cost of the farm to its actual cost:

$E E_{\mathrm{i}}=\frac{w_{i}{ }^{\prime} x_{i}^{*}}{w_{i}{ }^{\prime} x_{i}}$

Technical efficiency scores were obtained by solving the following programme:

$$
\begin{array}{ll} 
& \min _{\theta_{i}, \lambda} \theta_{i} \\
\text { Subject to } & -y_{i}+Y \lambda \geq 0, \\
& \theta_{i} x_{i}-X \lambda \geq 0, \\
& N 1^{\prime} \lambda=1, \\
& \lambda \geq 0, \\
& \theta_{i} \in(0,1]
\end{array}
$$

where $N 1^{\prime} \lambda=1$, is a constraint to ensure the assumption of VRS. Finally, the allocative efficiency scores were obtained by dividing the economic efficiency score with the technical efficiency score:

$A E_{i}=\frac{E E_{i}}{\theta_{i}}$

Each DEA equation, i.e. equation 1 and 3, was solved once for each farm in the sample. Further, the calculations in equation 2 and 4 were done once for each farm.

\section{Step 2: regressions analysis}

To assess the effect of differences in farm size, the efficiency scores were regressed on variables measuring farm size. Because efficiency scores cannot be larger than one, the censored, or tobit, model was used. The tobit model can be written as follows:

$$
\begin{aligned}
& y_{i}^{*}=\sum_{i} \beta x_{i}+\varepsilon_{i}, \quad i=1,2, \ldots . n, \\
& y_{i}=1 \quad \text { if } y_{i}^{*} \geq 1 \\
& y_{i}=y_{i}^{*} \quad \text { if } \quad y_{i}^{*}<1
\end{aligned}
$$

where $\varepsilon \sim N\left(0, \sigma^{2}\right)$ and the are the parameters for the explanatory variables. (For a review of tobit regression, see for example Hayashi 2000).

The combination of DEA efficiency scores and tobit regression is common in the literature, where examples include Sharma et al. (1999), Galanpoulos et al. (2006), Haji and Andersson (2006) and Barnes (2006). However, the approach was criticized by Simar and Wilson (2007) because the explanatory variables used in the second stage regression are likely to be correlated to the inputs and outputs used to estimate the first stage DEA efficiency scores, and because DEA scores can be biased in small samples. Instead, Simar and Wilson (2007) suggested two bootstrap algorithms to overcome these problems. Afonso and St Aubyn (2006) compared in an empirical setting the results from the bootstrap algorithms and the traditional twostage approach and found that both the estimated coefficients and the significance levels were very similar in all three cases. This questions the value of the extra computational burden caused by the bootstrap algorithms. Furthermore, Hoff (2007) compared empirically the DEA-tobit model with more complicated regression models and concluded that the tobit model is often sufficient to assess the second stage effects of DEA models.

\section{Step 3: scale efficiencies and effects}

DEA scale efficiencies, i.e. the extent to which the farm is operating at its economically optimal scale, were calculated by solving equation 3 again. However, this time the constraint $N 1^{\prime} \lambda=1$ was deleted to obtain a measure of technical efficiency under the assumption of constant returns to scale (CRS). The scale efficiency $\left(\mathrm{SE}_{i}\right)$ of each farm was then calculated as follows:

$S E_{i}=\frac{T E_{C R S_{i}}}{T E_{V R S_{i}}}$

where $T E_{C R S_{i}}$ is the technical efficiency of farm $i$ under the assumption of CRS, and is the technical efficiency of farm $i$ under the assumption of VRS. 
Hansson, H. Are larger farms more efficient?

To identify the scale type ${ }^{2}$ at which the firm is operating, equation 3 was solved once more, but this time the constraint $\mathrm{N} 1^{\prime} \lambda=1$ was changed to $N 1 ' \lambda \leq 1$, to impose non-increasing returns to scale. If the new technical efficiency score obtained is equal to the one obtained by imposing variable returns to scale, the firm is operating at decreasing returns to scale (DRS); otherwise it is operating at increasing returns to scale (IRS). A firm operating at its optimal scale, i.e. at CRS was identified by investigating whether $T E_{C R S_{i}}=T E_{V R S_{i}}$, where equality means that the farm is operating under CRS. (See for example Coelli et al. 2005). As was stressed in Forsund and Hjalmarsson (2004), DEA scale efficiency scores may depend on the orientation (input or output) in the analysis. As a consequence the procedure followed in this paper should be interpreted in light of the input-oriented DEA analysis.

\section{Data and description of the studied farms}

Farm level accounting data from Statistics Sweden were used in this study. Statistics Sweden collects detailed information about the farms' individual balance sheets and income statements. The dataset is an unbalanced panel and stratified according to farm size and geographical location. Regional price data from a database ${ }^{3}$ consisting of gross margin

2 A firm can be operating under either constant, increasing or decreasing returns to scale. Constant returns to scale refers to a situation where the percentage increase in total costs is equal to the percentage change in output when the firm increases its output. Increasing returns to scale refers to a situation where the percentage increase in total cost is less than the percentage change in output, when the firm increases its output. Decreasing returns to scale refers to a situation where the percentage increase in total cost is larger than the percentage change in total output, when the firm increases its output.

3 Agriwise, published by the department of economics, SLU, Sweden. budgets for different agricultural production lines and regions in Sweden were used when it was not possible to calculate the prices directly from the accounting data. This means a use of standard prices, which do not take into account the possibility of negotiating prices. Therefore, the actual inputs of farms that can negotiate prices may be underestimated, and as a result their efficiency scores overestimated.

Only specialized dairy farms, defined as farms where the income from milk is at least $75 \%$ of the total income, were studied. Furthermore, farms with a milk production of less than 160,000 litres per year, i.e. a herd size of approximately 20 cows were deleted from the dataset, to get a dataset with an average herd size that reflects the real average herd size in Sweden according to the latest official statistics. This also avoids influence from farms that are likely to have quitted dairy production since the data were collected. In total, 209 farms were studied. The dataset is an unbalanced data panel starting in 1998 and ending in 2002. To take stochastic variation in the data, to which DEA is sensitive, into consideration each farm was represented by its own average of inputs, outputs and prices. Each farm was thus represented by its own average size over the years it participated in the dataset. The number of dairy cows was not explicitly included in the dataset. However because the distribution of the number of cows in the sample is relevant background information to the study, the number of dairy cows was approximated by assuming that each cow on average yielded 8000 litres of milk per year. In Figure 2, the distribution of the number of cows in the sample is shown. The figure shows that there is a large variation in the number of cows in the sample.

\section{Variables used in the efficiency estimations}

Inputs were aggregated into six variables: fodder, labour, capital, energy, seed and fertilizer, which are considered as the main purchased inputs of a dairy farm. The fodder variable consisted mainly of 
Vol. 17 (2008): 325-337.

Number of farms

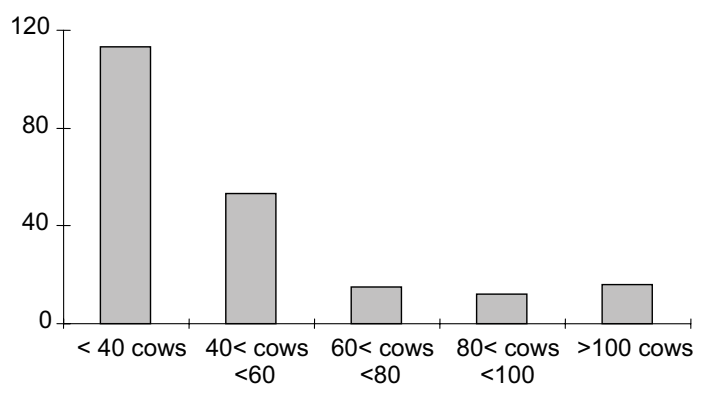

Fig. 2. The distribution of cows in the sample.

concentrate and mineral fodder. Labour represented the total labour need at the farm and consisted of both family labour and hired labour. Capital was a measure, in SEK, of production rights, fixed equipments and buildings. Energy was a measure of the amount of oil and electricity used. Seed and fertilizer measured how many kilograms of each were used. Because inclusion in the sample was based on the farms' degree of specialization in milk production, outputs consisted mainly of milk. However, the farms also used their inputs to produce other outputs than milk, such as livestock, crop and forage. Total outputs were therefore aggregated into a single measure of farm output: total revenue.

Two different measures of size were considered: income from milk and number of hectares. Income from milk measured the size of the dairy production and the number of hectares measured the physical size of the farm. It would have been more preferable to measure the size of dairy production in the number of cows at the farm; however, this measure was not available for all farms in our dataset. To account for the possibility of non-linear effects, squared measures of the size variables were also included in the regressions.

Summary statistics of the data are contained in Table 1.

To account for differences in efficiency due to differences in geographical location, dummy variables representing different geographical lo- cations were used. In official statistics, Sweden is normally divided into eight production areas, according to Figure 3. These production areas were used as indicators of geographic location.

To avoid perfect multicollinearity, the dummy variables for location in area 8 , Nö, northern Sweden, were not included in the regressions. This implies that the coefficients of the geography dummies should be interpreted as the relative effect compared to being located in northern Sweden.

Table 1. Summary statistics of the variables in the study.

\begin{tabular}{|c|c|c|}
\hline & \multicolumn{2}{|c|}{$\begin{array}{c}\text { Figures based on } \\
209 \text { specialized } \\
\text { dairy farms }\end{array}$} \\
\hline & Mean & $\begin{array}{l}\text { Standard } \\
\text { deviation }\end{array}$ \\
\hline Fodder (kilograms) & 230961 & 205626 \\
\hline Labour (hours) & 5042 & 1935 \\
\hline Capital (SEK) & 1038829 & 1133996 \\
\hline Energy (units) & 127660 & 94242 \\
\hline Seed (kilograms) & 6110 & 5806 \\
\hline Fertilizer (kilograms) & 5159 & 4466 \\
\hline Total income (100000 SEK) & 14.01 & 10.28 \\
\hline \multicolumn{3}{|c|}{ Prices (SEK per kilogram unless otherwise stated) } \\
\hline Price of fodder & 1.52 & 0.25 \\
\hline Price of labour (SEK/hour) & 95.83 & 4.26 \\
\hline Interest rate & 0.065 & 0.011 \\
\hline Price of energy (SEK/units) & 0.61 & 0.19 \\
\hline Price of seed & 2.76 & 0.14 \\
\hline Price of fertilizer & 7.65 & 0.66 \\
\hline \multicolumn{3}{|l|}{ Measures of size } \\
\hline Income from milk (100000 SEK) & 11.53 & 8.62 \\
\hline Number of hectares & 68 & 43 \\
\hline
\end{tabular}

To avoid biases due to inflation, the monetary values were deflated to the price level of the first year in the panel, i.e. 1998. In 1998, 1 USD was equal to approximately 8 SEK. 
Hansson, H. Are larger farms more efficient?

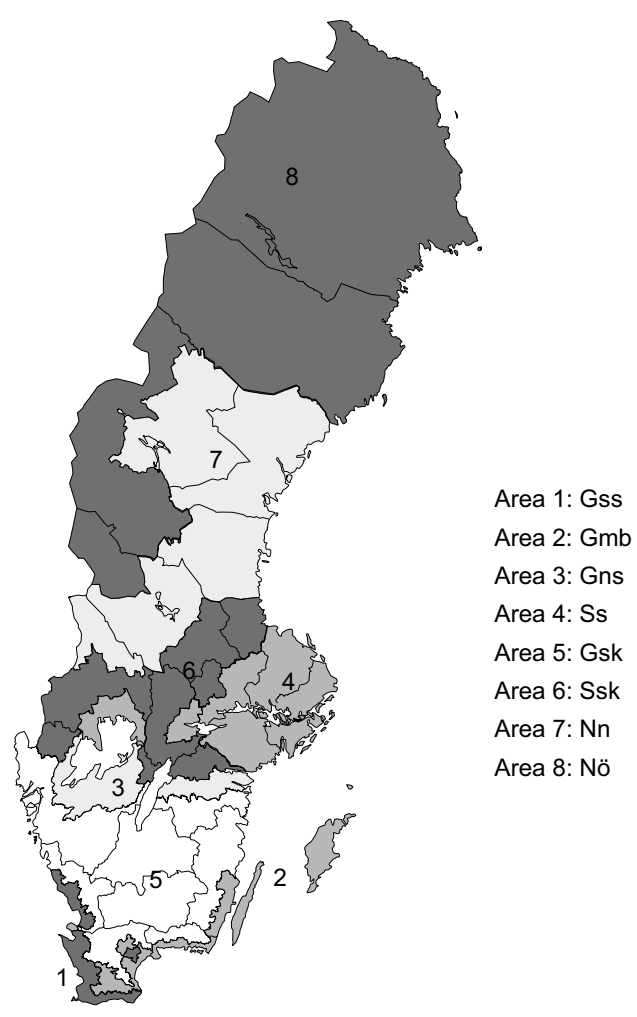

Fig. 3. Production areas in Sweden. Source: Statistics Sweden pers. comm. 2006

\section{Results}

\section{Descriptive statistics of the efficiency results}

Farm level economic, technical and allocative inputoriented efficiencies were calculated according the method outlined above. The results are shown in Table 2.

The results reported in Table 2 show that efficiency could increase if all farms were as efficient as the most efficient farms in the sample. The main cause of low economic efficiency is the low allocative efficiency, i.e. insufficient cost minimization. The distributions of both the technical and allocative efficiencies are skewed towards full efficiency;
Table 2. Mean, minimum (min), standard deviation (std) and distribution of the economic, technical and allocative input efficiencies.

\begin{tabular}{lccc}
\hline & $\begin{array}{c}\text { Economic } \\
\text { efficiency }\end{array}$ & $\begin{array}{c}\text { Technical } \\
\text { efficiency }\end{array}$ & $\begin{array}{c}\text { Allocative } \\
\text { efficiency }\end{array}$ \\
\hline Mean & 0.696 & 0.877 & 0.795 \\
Min & 0.357 & 0.495 & 0.395 \\
Std & 0.136 & 0.123 & 0.106 \\
Number of fully & 5 & 60 & 5 \\
efficient farms & 0.107 & -0.829 & -0.550 \\
Skewness & -0.190 & -0.053 & 0.992 \\
Kurtosis & & &
\end{tabular}

however the distributions of economic efficiencies are skewed towards lower efficiency. This implies that a larger part of the farms have a high technical and allocative efficiency, whereas a larger part of the farms have low economic efficiency.

The farms were sorted according to their economic efficiency results, a measure which shows the overall efficiency of the farms, and grouped into four groups each containing $25 \%$ of the farms. Average economic efficiency, income from dairy and number of hectares were then calculated for each group. The results are contained in Table 3.

The results in Table 3 show that the $25 \%$ most efficient farms, on average, is also the group with the largest average dairy production. This was also confirmed in a significant t-test. However, this group seems to be smaller in terms of the number of hectares. It is interesting to note that the farms in the second highest efficiency quartile are, on average, the smallest farms in both size classes. The fact that the farms in the second most efficient quartile are the smallest farms was also confirmed by significant t-tests.

\section{Tobit regression results}

The influence on farm level efficiency of differences in farm size was also assessed by tobit regression, according to the method outlined above. Because 
Vol. 17 (2008): 325-337.

Table 3. Average size of farms in different economic efficiency quartile classes.

\begin{tabular}{|c|c|c|c|c|c|c|}
\hline & \multicolumn{2}{|c|}{$\begin{array}{l}\text { Average economic } \\
\text { efficiency }\end{array}$} & \multicolumn{2}{|c|}{$\begin{array}{l}\text { Average income from dairy } \\
\qquad(100000 \text { SEK })\end{array}$} & \multicolumn{2}{|c|}{$\begin{array}{c}\text { Average number of } \\
\text { hectares }\end{array}$} \\
\hline & Mean & $\begin{array}{l}\text { Standard } \\
\text { deviation }\end{array}$ & Mean & $\begin{array}{l}\text { Standard } \\
\text { deviation }\end{array}$ & Mean & $\begin{array}{l}\text { Standard } \\
\text { deviation }\end{array}$ \\
\hline The highest quartile & 0.873 & 0.067 & 13.54 & 13.18 & 72.45 & 56.13 \\
\hline The second highest quartile & 0.737 & 0.030 & 9.61 & 5.81 & 55.60 & 32.68 \\
\hline The third highest quartile & 0.647 & 0.025 & 11.53 & 8.01 & 64.44 & 35.20 \\
\hline The lowest quartile & 0.530 & 0.065 & 11.45 & 4.82 & 77.43 & 42.02 \\
\hline
\end{tabular}

the size measures are likely to be correlated, three models were estimated, once for each efficiency measure. In the first model, the size of the dairy production was included. In the second model, the effect of the physical size in terms of the number of hectares was considered. In the third model, finally, all three size measures were included. In all three regression models, the effect of geographic location was controlled for. The regression results are presented in Table 4.

Both the size of the dairy production and the physical size of the farm significantly affect economic and technical efficiency; however only the size of the dairy production significantly affects allocative efficiency. In all cases where the linear effects are significant, so are also the squared effects, suggesting that farm size affects efficiency in a non-linear way. Further, all significant squared effects are positive which indicate that efficiency is first decreasing with farm size and then increasing.

Geographic location influence especially technical efficiency, indicating that the technical efficiency of the farms differ depending on what region the farm is situated in. The results also show that allocative efficiency is not affected by geographic location and that economic efficiency is affected only on a few occasions by geographic location. This suggests that the possibilities of the farmers to combine inputs in the optimal way are not affected by geographic location.

\section{Farm level scale efficiency and effects}

Scale efficiencies and effects were calculated according to the method outlined above. The results are contained in Table 5 .

The average level of scale efficiency was $94.7 \%$. This means that the farms operate close to their long-run optimal scale. The distribution of scale efficiency is skewed towards full scale efficiency which also indicates that the farms are close to their optimal scales. However, the results also show that several farms operate under increasing returns to scale and should thus be able to increase their efficiency by growing. On the other hand, a closer look at these particular farms reveals that the average scale efficiencies of the IRS farms are high, $92.5 \%$ which means that they are close to their optimal scale, even though operating under IRS.

\section{Discussion}

This study aimed to investigate how farm economic, technical and allocative input efficiencies of specialized dairy farms in Sweden were affected by differences in farm size. The study was motivated by the changing dairy farm structure that is occurring in Sweden and other North European countries, where the number of dairy farms decreases rapidly, meanwhile the remaining farms get larger. In this 
Hansson, H. Are larger farms more efficient?

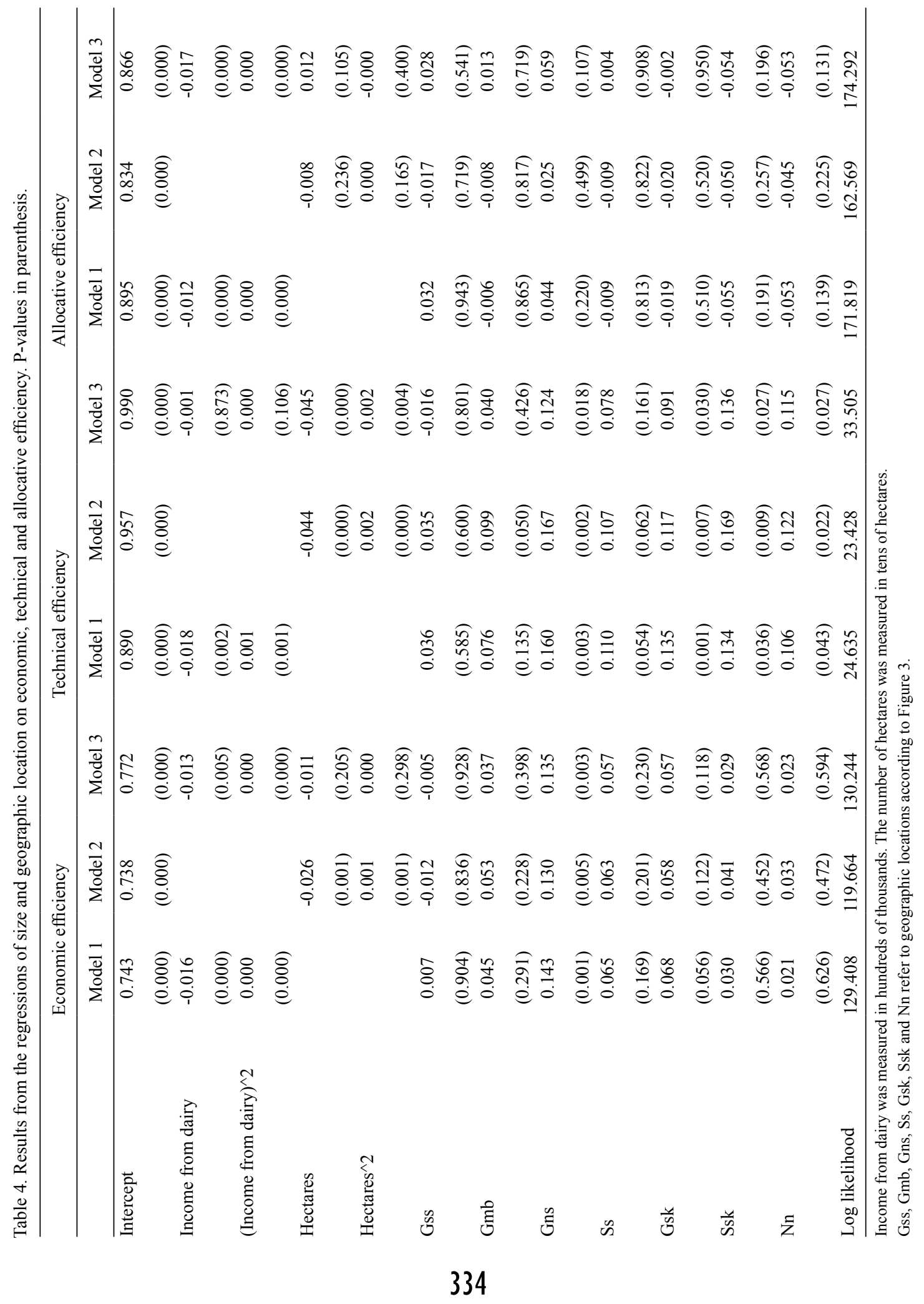


Vol. 17 (2008): 325-337.

Table 5. Mean, minimum, standard deviation and distribution of the scale efficiency results.

\begin{tabular}{lc}
\hline Mean & 0.947 \\
Standard deviation & 0.065 \\
Minimum & 0.654 \\
Skewness & -1.576 \\
Kurtosis & 2.358 \\
Number of farms operating under $\mathrm{CRS}^{1}$ & 42 \\
Number of farms operating under $\mathrm{IRS}^{2}$ & 133 \\
Number of farms operating under $\mathrm{DRS}^{3}$ & 34 \\
\hline${ }^{1}$ Constant returns to scale & \\
${ }^{2}$ Increasing returns to scale & \\
${ }^{3}$ Decreasing returns to scale &
\end{tabular}

setting it is important to understand if and how farm efficiency, and in the continuation, farm profits, are affected by farm size. The results in this study are important because they show in several dimensions how efficiency is affected by farm size. The effects of farm size are evaluated for all major input-oriented efficiency scores. Further, both the linear and squared effects of farm size are considered. Previous literature does not give sufficient advice on how dairy farms in North European countries are affected by the structural change, because it does not show a clear, unambiguous relation between efficiency and size. Further previous literature does not easily apply to north European countries because of differences in e.g. farming systems, climate and culture.

The efficiency results reported in this paper show that especially the average technical efficiency score is the higher score. Further, the average allocative efficiency scores are lower than the average technical efficiency scores. This implies that the main reason for economic inefficiency is low allocative efficiency. This study shows, like other literature (e.g. Oude Lansink et al. 2002, Reinhard et al. 2000, Heshmati and Kumbhakar 1994) that efficiency could increase if all farms were as efficient as the most efficient farms. The average technical efficiency scores found in this paper are generally higher than those found in the studies referred to above. However, based on comparisons between our study and other efficiency studies, it is not possible to argue how much more or less efficient Swedish dairy farms are compared to other farms in other countries because efficiency is a relative concept based on the sample and because of differences in the methodology choice or in the variable specification (see for example Coelli et al. 2005).

Considering two measures of size in the second-stage regressions; the size of the dairy production (income from dairy) and the physical size of the farm (the number of hectares) and controlling for differences in geographical regions, farm size was found to typically influence efficiency in a non-linear way. In particular, the results suggest that both economic and technical efficiencies are first negatively influenced by both concepts of farm size and then positively influenced by farm size. Allocative efficiency, on the other hand, is not affected by the physical size of the farm, but by the size of the dairy production. Also in this case, efficiency is typically first decreasing with farm size and then increasing. A plausible reason for the observed non-linear relationships between farm size and efficiency is that to efficiently use technology associated with larger scale farming, a reasonably large farm is required. Therefore, modest growth among the smallest farms may not lead to more efficient farms, indeed it may decrease efficiency.

Our results are somewhat different from previous literature studying the relationships between farm efficiency and the size of the dairy production. For example, based on a division of their sample into three groups, Bravo-Ureta and Rieger (1991) found negative relationships between the size of the dairy herd and economic as well as allocative efficiencies, but a positive relationship between technical efficiency and farm size. Further, Alvarez and Arias (2004), Barnes (2006) and Hadley (2006) found that technical efficiency in dairy farms was positively affected by farm size, as measured by the size of the dairy production. Neither of the two referred studies included squared measures of farm size.

Compared to results from outside the dairy sector, the results reported here are similar to results reported by Helfand and Levine (2004) who found that technical efficiency was first decreasing and 
Hansson, H. Are larger farms more efficient?

then increasing with farm size. Our results differ from those of Sharma et al. (1999) who found positive linear relationships between all major efficiency scores, i.e. economic, technical and allocative efficiency and farm size.

The average scale efficiency was $94.7 \%$. This result suggests that, on average, the studied farms are operating close to their optimal scales. This in turn suggests that the farmers would not gain much in terms of efficiency by being at a more optimal scale. Looking at the scale effects, several farms are characterized by increasing returns to scale and thus should be able to increase their earnings by enlarging their size: however, the average scale efficiency is high also in this group with an average score of $92.5 \%$. The results imply that there is a potential efficiency gain from increasing farm size to operate at a more optimal scale, but that its magnitude may not be very large.

\section{Conclusions and suggestions}

The results on especially economic and allocative efficiency scores show that the farms can become more efficient if they became better at combining their inputs in the cost minimizing way, while remaining at the same farm size. Furthermore, the regression results suggest efficiency is typically first decreasing and then increasing with farm size. Therefore, this paper suggests two ways to increase efficiency among dairy farms.

First, increased efficiency can be achieved by focusing on increasing the knowledge about how inputs can be combined more optimally. This suggestion is supported by Rodgers (1994) who argued that the farm market or the farm technology is not the cause of the low farm earnings. Rather, Rodgers (1994) stressed the importance of improving the human capital and concluded that the main tool to increase farm earnings was to increase the human capital. If the farmers were better at combining their inputs optimally according to input prices, their overall economic efficiency would increase because their allocative efficiency would increase.
A concrete way to achieve this would be to develop tools to assist the farmers in valuing their inputs.

Second, increased efficiency can be achieved by focusing on farm growth. However, because efficiency is typically first decreasing and then increasing with farm size, this strategy requires that the farmers aim for farm sizes in the larger size segments if the strategy is to lead to more efficient farms.

Acknowledgements: I am grateful to Prof. Bo Öhlmér and Prof. Hans Andersson for valuable comments on earlier drafts. The paper has also benefited from comments from the Editor and from two anonymous Referees. The study was financed by the Swedish Farmers' Foundation for Agricultural Research (SLF), Sweden, to whom I also express my gratitude.

\section{References}

Afonso, A. \& St. Aubyn, M. 2006. Cross-country efficiency of secondary education provision: A semi-parametric analysis with on-discretionary inputs. Economic Modelling 23: 476-491.

Aigner, D., Lovell, C.A.X \& Schmidt, P. 1977. Formulation and Estimation of Stochastic Frontier Production Function Models. Journal of Econometrics 6: 21-37.

Alvarez, A. \& Arias, C. 2004. Technical efficiency and farm size: a conditional analysis. Agricultural Economics 30: 241-250.

Balcombe, K., Fraser, I. \& Kim, J.H. 2006. Estimating technical efficiency of Australian dairy farms using alternative frontier methodologies. Applied Economics 38. 221-2236.

Barnes, A.P. 2006. Does multi-functionality affect technical efficiency? A non-parametric analysis of the Scottish dairy industry. Journal of Environmental Management. 80: 287-294.

Bravo-Ureta, B.E. \& Rieger, L. 1991. Dairy Farm Efficiency Measurement Using Stochastic Frontiers and Neoclassical Duality. American Journal of Agricultural Economics 73: 421-428.

Charnes, A., Cooper, W. W., \& Rhodes, E. 1978. Measuring the Efficiency of Decision Making Units. European Journal of Operational Research 2: 429-444.

Coelli, T. \& Perelman, S. 1999. A comparison of parametric and non-parametric distance functions: With application to European railways. European Journal of Operational Research 117: 326-339.

Coelli, T., Rao, P. D. S., O'Donnell, C. J., \& Battese, G. E. 2005. An Introduction to Efficiency and Productivity Analysis. Springer Science+Business Media Inc. New York. 
Vol. 17 (2008): 325-337.

Cullinane, K., Wang, T-F., Song, D-W. \& Ji, P. 2006. The technical efficiency of container ports: Comparing data envelopment analysis and stochastic frontier analysis. Transportation Research Part A 40: 354-374.

Farrell, M. J. 1957. The Measurement of Productive Efficiency. Journal of the Royal Statistical Society Ser. A 120: 253-281

Forsund, F.R. \& Hjalmarsson, L. 2004. Calculating Scale Elasticity in DEA Models. The Journal of the Operational Research Society 55, p. 1023-1038.

Galanopoulos, K., Aggelopoulos, S., Kamenidou, I. \& Mattas, K. 2006. Assessing the effects of managerial and production practices on the efficiency of commercial pig farming. Agricultural Systems 88: 125-141.

Gasson, R. 1973. Goals and values of farmers. Journal of Agricultural Economics 24: 521-542.

Hadley, D. 2006. Patterns in Technical Efficiency and Technical Change at the Farm-level in England and Wales, 1982-2002. Journal of Agricultural Economics 57: 81-100.

Haji, J. \& Andersson, H. 2006. Determinants of efficiency of vegetable production in smallholder farms: The case of Ethiopia. Food Economics - Acta Agriculturae Scandinavica C 3: 125-137.

Hayashi, F. 2000. Econometrics. Princeton University Press. New Jersey.

Helfand, S., M. \& Levine, E. S. 2004. Farm size and the determinants of productive efficiency in the Brazilian Center-West. Agricultural Economics. 31:241-249.

Heshmati, A. \& Kumbhakar, S. C. 1994. Farm Heterogeneity and Technical Efficiency: Some Results from Swedish Dairy Farms. The Journal of Productivity Analysis. 5: 45-61.

Hoff, A. 2007. Second stage DEA: Comparison of approaches for modelling the DEA score. European Journal of Operational Research. 181, 425-435.

Iráizoz, B., Rapún, M., \& Zabaleta, I. 2003. Assessing the technical efficiency of horticultural production in Navarra, Spain. Agricultural Systems. 78: 387-403

Karagiannis, G., Midmore, P. \& Tzouvelekas, V. 2002. Separating Technical Change from Time-Varying Technical Inefficiency in the Absence of Distributional Assumptions. Journal of Productivity Analysis. 18: 23-38.

Lunneryd, D. 2003. Unique Decision Making with Focus on Information Use - The case of converting to organic milk production. Acta Universitatis Agriculturae Sueciae. Agraria 405. Swedish University of Agricultural Sci- ences, Uppsala, Sweden.

MacDonald, J,M., O'Donoghue, E.J, McBride, W.D., Nehring, R.F., Sandretto, C.L. \& Mosheim, R. 2007. Profits, Costs, and the Changing Structure of Dairy Farming. Economic Research report no 47. USDA Economic Research Service, Washington D.C., U.S.

Meeusen, W. \& van den Broeck, J. 1977. Efficiency Estimatin from Cobb-Douglas production functions with composed errors. International Economic Review. 18: 435-444.

Newman, C. \& Matthews, A. 2006. The productivity performance of Irish dairy farms 1984-2000: a multiple output distance function approach. Journal of Productivity Analysis. 26: 191-205.

Oude Lansink A., Pietola, K. \& Bäckman, S. 2002. Efficiency and productivity of conventional and organic farms in Finland 1994-1997. European Review of Agricultural Economics. 29: 51-65

Penrose, E. 1959. The theory of the growth of the firm. Oxford, UK.

Reinhard, S., Knox Lowell, C. A. \& Thijssen, G. J. 2000. Environmental efficiency with multiple environmentally detrimental variables; estimated with SFA and DEA. European Journal of Operational Research. 121: 287-303.

Resti, A. 1997. Evaluating the cost-efficiency of the Italian Banking System: What can be learned from the joint application of parametric and non-parametric techniques. Journal of Banking \& Finance. 21: 221-250.

Rodgers, J. L. 1994. Differential human capital and structural evolution in agriculture. Agricultural Economics. 11: 1-17.

Sharma, K. R, Leung, P., \& Zaleski, H. M. 1999. Technical, allocative and economic efficiencies in swine production in Hawaii: a comparison of parametric and nonparametric approaches. Agricultural Economics. 20: 23-35

Simar, L. \& Wilson, P.W. 2007. Estimation and inference in two-stage, semi-parametric models of production processes. Journal of Econometrics. 136: 31-64.

Statistics Sweden. 2002. Jordbruksstatistisk årsbok 2002. Statistics Sweden, Örebro, Sweden.

Statistics Sweden. 2006. Jordbruksstatistisk årsbok 2006. Statistics Sweden, Örebro, Sweden.

Statistics Sweden. 2007. Jordbruksstatistisk årsbok 2007. Statistics Sweden, Örebro, Sweden.

Tauer, L. W. \& Mishra, A. K. 2006 Can the small dairy farm remain competitive in US agriculture? Food Policy. 31: 458-468. 